\title{
Social Comparisons on Self-Perception and Mate Preferences: The Self and the Others
}

\author{
Felipe Nalon Castro*, Wallisen Tadashi Hattori, Maria Emília Yamamoto, \\ Fívia de Araújo Lopes \\ Laboratory of Evolution of the Human Behavior, Graduate Program in Psychobiology, Department of \\ Physiology, Federal University of Rio Grande do Norte, Natal, Brazil \\ Email: ${ }^{*}$ castrofn@gmail.com, wallhattori@gmail.com, emiliayamamoto@gmail.com, fivialopes@gmail.com
}

Received 2 March 2014; revised 5 April 2014; accepted 1 May 2014

Copyright (C) 2014 by authors and Scientific Research Publishing Inc.

This work is licensed under the Creative Commons Attribution International License (CC BY). http://creativecommons.org/licenses/by/4.0/

c) (†) Open Access

\section{Abstract}

This study aimed to investigate the effect of social comparison on self-perception and mate preferences. For this purpose, 225 undergraduate student participants provided their self-perception before and after evaluating descriptions of stimuli subjects specifically developed with high or low levels of physical, social and status related attributes. Participants also provided a description of their ideal short- and long-term partner. We hypothesized that self-evaluations and mate preferences change in response to exposure to competitors with different levels of reproductively relevant attributes. Results indicated that individuals were aware of the characteristics valued by the opposite-gender in the mating market and that self-evaluation was affected by the attributes of other people. No effect of social comparison on mate preferences was observed. These findings advance our understanding of the mate selection process by contributing more evidence that one's own perceptions of mate value seem to be affected by the values of other individuals. Attention to the reproductively relevant attributes of others can help individuals optimize the time and energy invested in mate selection and determine the mating tactic most appropriate to a specific social environment.

\section{Keywords}

Mate Value, Physical Attractiveness, Reproduction, Social Skills, Social Status

\section{Introduction}

Various lines of evidence suggest that same-gender social comparison can affect self-perceived mate value in

*Corresponding author.

How to cite this paper: Castro, F. N., Hattori, W. T., Yamamoto, M. E., \& de Araújo Lopes, F. (2014). Social Comparisons on Self-Perception and Mate Preferences: The Self and the Others. Psychology, 5, 688-699. 
both males and females, which in turn is related to mate preferences and behavior. In this context, knowledge about one's own mate value in the face of potential competitors can be beneficial, by optimizing the investment of time and energy in partner choice and the expression of different mating tactics (Gilbert et al., 1995; Little \& Mannion, 2006). The current study builds on these previous findings by investigating the effect of social comparison on self-evaluation and mate preferences using same-gender stimuli subjects (SS) based on social skills characteristics, as well as physical and status attributes. We aim to address the following points: a) to determine, for male and female participants, if different levels of specific reproductively relevant attributes (physical attractiveness, social skills or social status) affect the opposite sex's perception of the overall desirability of samegender SS; b) to identify whether self-perception in male and female participants is affected by their exposure to different attributes of same-gender SS; and c) to verify if the sexual preferences of male and female participants in assessing ideal short- and long-term partners are affected by exposure to same-gender SS with different traits.

Our main hypothesis is that the self-perception and mate preferences of male and female participants will change in response to exposure to competitors with different levels of reproductively relevant attributes. This hypothesis may be further broken down into the following specific predictions:

1) Intrasexual evaluations: a) female participants will evaluate women of high physical attractiveness as more desirable to the opposite sex, compared to women of low physical attractiveness; b) male participants will evaluate men with high, current or prospective, social status as more desirable to the opposite sex, compared to men with low social status; c) male and female participants will evaluate same-gender SS with high social skills as more desirable to the opposite sex, compared to those with low social skills.

2) Social comparison and self-perception: a) exposure to women with high and low physical attractiveness will cause a respective decrease and increase in self-perception by female participants; b) exposure to men with high and low social status will cause a respective decrease and increase in self-perception by male participants; c) exposure to same-gender SS with high and low social skills will cause a respective decrease and increase in self-perception.

3) Social comparison and mate preferences: a) female participants exposed to women of high physical attractiveness will show less demanding ideals for short- and long-term romantic partners, compared to female participants exposed to women of low physical attractiveness; b) male participants exposed to men of high social status will show less demanding ideals for short- and long-term romantic partners, compared to male subjects exposed to men of low social status; c) male and female participants exposed to same-gender SS with high social skills will show less demanding ideals for short- and long-term romantic partners, compared to those exposed to SS with low social skills.

\section{Literature Review}

Nature provides many examples in which one individual evaluates conspecifics—usually of the same sex-to decide if he/she is willing, or not, to challenge another individual for access to a resource of interest (Gilbert, Price, \& Allan, 1995). Several studies have presented evidence that a related process occurs among humans (Festinger, 1954; Kemmelmeier \& Oyserman, 2001; Little \& Mannion, 2006; Wade \& McCrea, 1999; Wilcox \& Laird, 2000). In fact, social comparison seems to be a common event, that even occurs when we are not consciously aware of it (Stapel \& Blanton, 2004). However, people display different outcomes, such as changes in self-evaluation and self-esteem in downward or upward comparisons of themselves to individuals considered better or worse than themselves with respect to some specific attribute (Kemmelmeier \& Oyserman, 2001; Suls, Martin, \& Wheeler, 2002; Taylor \& Lobel, 1989).

An interesting outcome that demonstrates this phenomenon comes from tennis matches. Not surprisingly, players who have just won a match show higher levels of perceived athletic competence compared to those who have just lost, but only those who have lost to a lower-ranked player show a decrease in their self-evaluation (Bardel, Fontayne, Colombel, \& Schiphof, 2010). Another study demonstrated that people with independent orientation when compared to others who are perceived as successful usually made negative judgments about themselves (contrast effect); in contrast, interdependent people showed an increase in their self-evaluation (assimilation effect) (Kemmelmeier \& Oyserman, 2001). Furthermore, the literature suggests that self-perceived physical attractiveness can modulate a person's willingness to engage in cooperative activities (Mulford, Orbell, Shatto, \& Stockard, 1998) or feeding behavior (Harrison, Taylor, \& Marske, 2006). 
The act of comparing oneself to others is an important part of our social environment and probably has a strong evolutionary basis because it can affect the way people perceive themselves, their sense of well-being, the level of effort invested —and thus performance-in an activity and help us take a position in imminent conflict situations (Bardel et al., 2010; Gilbert, et al., 1995; Suls et al., 2002). When it comes to mating behavior, characteristics specifically related to the perception of potential mate value become more relevant.

Fisher, Cox, Bennett and Gavric (2008) defined mate value as the "total sum of characteristics an individual possesses at a given moment and within a particular context that impacts on their ability to successfully find, attract, and retain a mate". Several studies indicate that characteristics associated with social skills are most important in forging romantic relationships. However, men and women tend to value different attributes in their mating partners, with the current pattern suggesting that men assign greater value to physical attractiveness, while women prefer mates with attributes associated with higher social-status (Buss, 1989; Buss \& Barnes, 1986; Buunk, Dijkstra, Fetchenhauer, \& Kenrick, 2002; Castro \& Lopes, 2011; Kenrick, Kenrick, Sadalla, Groth, \& Trost, 1990; Li, Bailey, Kenrick, \& Linsenmeier, 2002; Sprecher, Sullivan, \& Hatfield, 1994; Woodward \& Richards, 2005). One of the theories aiming to explain these observations is the sexual strategies theory (Buss \& Schmitt, 1993), which appeals to the differential investment males and females make in their offspring. For males is a facultative investment of time, energy and resources, and for females is obligatory/largely physiological investment and infant care (Trivers, 1972), which imposed different selective pressures to our ancestors, and resulted in mate preferences to deal with partner choice. Evidence supporting this evolutionary explanation comes from studies of different cultures (Buss, 1989; Lippa, 2007) and is consistent through time (Buss, Shackelford, Kirkpatrick, \& Larsen, 2001; Gallant, Williams, Fisher, \& Cox, 2011; Hill, 1945; McGinnis, 1958). Thus, one may predict that relevant reproductive characteristics can affect self-perceived mate value because these traits are important in establishing romantic relationships.

What, however, are the effects of social comparison on the self-perceived mate value on men and women? A number of studies have demonstrated the effects of social comparison on human mate value and mate preferences. For example, exposure to pictures of same-gender individuals with higher degrees of physical attractiveness seems to affect several people's assessments of body- and self-esteem (Grogan, Williams, \& Conner, 1996; Mills, Polivy, Herman, \& Tiggemann, 2002; Wilcox \& Laird, 2000). Changes in self-esteem are important because this is strongly related to perceptions of mate-value (Brase \& Guy, 2004; Wade, 2000, 2003). Wade and McCrea (1999) found that men exposed to physically dominant and attractive men showed a decrease in their self-ratings of personality characteristics and that exposure to physically attractive men also decreased their self-ratings of attractiveness. A tendency towards dissatisfaction with one's own body was observed for both men and women after viewing same-sex individuals possessed of ideal body images (for review, see Blond, 2008; Groesz, Levine, \& Murnen, 2002). Furthermore, Gutierres, Kenrick and Partch (1999) showed that self-evaluation of their own desirability decreased in men after exposure to socially dominant men, but was not affected by exposure to physically attractive men. On the other hand, self-evaluation of their own desirability in women was significantly lower after exposure to physically attractive women, but was unaffected by exposure to the profiles of socially dominant women.

In a study of unmarried individuals, Bredow, Huston and Glenn (2011) observed that people who believe they possess low mate value in their local mating marketplace feel less confident about their chances of getting married. This result demonstrates the influence of social comparison on people`s romantic decisions, because expectations about getting married seem to predict the likelihood of a person getting married (Brown, 2000; Waller \& McLanahan, 2005). Other studies have found an association between self-perception and mate preferences (Bereczkei, Voros, Gal, \& Bernath, 1997; Little, Burt, Penton-Voak, \& Perrett, 2001; Vukovic, Feinberg, Jones, DeBruine, Welling, Little, \& Smith, 2008), self-perception and sexual behavior (Weeden \& Sabini, 2007), self-perception and partner choice (Buston \& Emlen, 2003; Castro, Hattori, \& Lopes, 2012) and even connections among social comparison, self-perception and mate preferences (Little \& Mannion, 2006), supporting the general evolutionary hypothesis to explain mate value and romantic relationships as previously presented.

\section{Methodology}

\subsection{Participants}

A total of 225 undergraduate students, between the ages of 18 and 29 years old, voluntarily participated in the current study. This sample was composed of 76 men $(M=22.03, S D=2.73$ years old $)$ and 149 women $(\mathrm{M}=$ 
21.04, SD $=2.60$ years old). According to the Brazilian classification standards for skin color (IBGE, 2010b), $45.3 \%$ of our sample was white, 39.1\% were pardo (mixed-race or dark-skinned individuals), $8.4 \%$ were yellow (Asian individuals: Japanese, Chinese, and Korean), 4.9\% were black, and 2.2\% were considered indigenous. All of the participants in this sample reported being attracted to the opposite sex. Data collection was performed in the city of Natal, the capital of Rio Grande do Norte, located in northeastern Brazil.

\subsection{Measures and Procedure}

The current study was realized during two discrete phases in which the participants first conducted a self-assessment and then evaluated specifically designed profiles of stimulus subjects (SS). In phase one, the participants were asked to provide some personal data and perform a self-evaluation of nine different traits by ranking them according to a 10-point Likert scale (0 - 9): attractive face, attractive body, good health, good financial status, sociability, ambition/hard worker, intelligence, agreeableness and sincerity. During the self-evaluation phase, subjects were also asked to assess their own overall desirability as a romantic partner by marking a reference point on a $100 \mathrm{~mm}$ line scale ranging from "not desirable at all" to "extremely desirable". In phase two, which was realized approximately 30 days after phase one was completed, participants were asked to evaluate eight same-gender SS, each consisting of a picture and a written description. These eight SS were described with the same specific combination of characteristics, i.e. similar physical attractiveness, social skills and social status. The participants evaluated the overall desirability expected from the opposite sex for each SS by marking a reference point on a $100 \mathrm{~mm}$ line scale ranging from "not desirable at all to the opposite sex" to "extremely desirable to the opposite sex". The subjects were then asked to perform a new self-evaluation identical to that conducted during phase one. Participants were also asked to describe, again using the same protocol as in phase one, their ideal short- and long-term romantic partner, using the same nine traits from self-evaluation.

All of the measurements in this study were collected using individual, anonymous questionnaires and the participants were not made aware of the purpose of the study during the experimental phases. The questionnaires from phases one and two were matched to each subject using individually selected passwords. To avoid any order effects, the SS profiles were randomly presented to the participants.

\subsection{Composition of Stimulus Subjects}

In phase two, the eight SS profiles were presented to subjects as a written description, followed by a photograph representing that particular profile. The photographs used in this study were selected from an image databank consisting of 60 males and 60 females, all with a smiling facial expression. In order to rank the images in terms of physical attractiveness, each picture was exposed by digital projector for four seconds to 20 individuals of the opposite sex to that of the photograph. These individuals had similar demographic characteristics to the study subjects, but were not part of the experimental sample. Each individual ranked the degree of physical attractiveness for the SS in each picture by marking a reference point along a $100 \mathrm{~mm}$ line scale ranging from "not attractive at all" to "extremely attractive". Photographs given a mean-physical-attractiveness ranking above $70 \mathrm{~mm}$ were randomly assigned to SS descriptions for "high-physical-attractiveness", while those given rankings under $30 \mathrm{~mm}$ were randomly assigned to SS descriptions for "low-physical-attractiveness". The SS in each photograph was also classified according to skin color (IBGE, 2010b). For this study we selected photographs of SS to represent the most abundant skin-color groups, i.e. white and pardo (dark-skinned) people, in the local population according to government census data from 2010 (44.96\% white; 49.04\% pardo; 0.98\% yellow; 4.91\% black; and $0.11 \%$ indigenous) (IBGE, 2010a).

The stimulus subject profiles were designed to cover all possible combinations of the three sets of characteristics used in this study: physical attractiveness, social skills, and social status, presented at one of two levels (high or low) according to a full-profile (full-concept) approach $(2 \times 2 \times 2)$ (Table 1$)$.

One example of a stimulus subject profile formulated for this study using highly rated attributes for the three sets of features for female participants is the following: "D. F. is an easy-going, competent woman. She is always helpful to other people even if she has to stop what she is doing. She became a government diplomat a few years ago. Now she has a good salary and few expenses so she has a lot of money to spend however she likes. Given her physical characteristics, many people find that D. F. is a very attractive woman; some say it's hard to take their eyes off her." Another stimulus subject profile formulated using low ranked attributes for the three sets of features for female participants is as follows: "Men consider M. H. terrible looking. She is self-centered 
Table 1. Stimulus subject profile combinations designed according to a full-profile approach for three sets of characteristics.

\begin{tabular}{cccc}
\hline Combinations & Physical attractiveness & Social skills & Social status \\
\hline 1 & High & High & Low \\
2 & High & High & High \\
3 & High & Low & Low \\
4 & High & Low & High \\
5 & Low & High & High \\
7 & Low & High & Low \\
\hline
\end{tabular}

and unreliable. She does not have many friends and even her closest friends do not enjoy spending time with her. She works as a waitress in a café that is near her home. Although she enjoys her job, she does not earn much money.” For male participants, the gender of each particular stimulus subject profile was changed.

\subsection{Analyses}

Three dichotomous variables were developed by independently grouping the study participants according to the SS that was evaluated (Table 1): 1) physical attractiveness at two ranking levels high physical attractiveness (combination 1, 2, 3 and 4) and low physical attractiveness (combination 5, 6, 7 and 8); 2) social skills at two ranking levels high social skills (combination 1, 2, 5 and 6) and low social skills (combination 3, 4,7 and 8); 3) current or prospective social status at two ranking levels high social status (combination 1, 3, 5 and 7) and low social status (combination 2, 4, 6 and 8). This approach ensured that contrasts between groups were made for only one type of attribute, as the value of other attributes varied, and allowed for more consistent comparisons to what might be expected in real-life events. The general mean for expected overall desirability for the eight SS evaluated by each participant and the difference-score between the second (phase two; post-exposure to SS) and first assessments (phase one; pre-exposure to SS) of the nine traits used in the self-evaluation protocol were also calculated, such that positive scores indicated an increase in self-assessments and negative scores a indicated a decrease in self-assessments.

In order to verify any differences for male and female participant's assessments of desirability for the different SS profiles, General Linear Model [GLM] tests were applied to each gender class. In these tests, the mean of the expected overall desirability of the SS was used as a dependent variable and dichotomous variables for physical attractiveness, social skills, and current or prospective social status were used as fixed factors $(2 \times 2 \times 2$ design). To identify whether the self-assessments of male and female participants were affected by exposure to SS with different levels of the specific attributes, two-tailed independent $t$ tests were applied for each of the characteristics used in the self-evaluation protocol. These tests were performed separately for male and female participants, to contrast those who evaluated the SS profiles with high or low quality attributes. In these tests, the difference-score between the first and second evaluations of each characteristic was used as a dependent variable and each of the dichotomous variables (physical attractiveness, social skills, and current or prospective social status) were used as independent variables. According to the same approach described for the self-assessment analyses, two-tailed independent $t$ tests were used to determine if individual sex preferences for ideal short- and long-term partners were affected by the SS traits, for each sex and relationship type. However, the preference score for each trait was used as dependent variable in these analyses. For all of the statistical tests employed here, the significance level was set at $5 \%$.

\section{Results}

\subsection{Intrasexual Evaluations}

Regarding the evaluations of overall desirability of same-gender SS, female participants assigned greater overall 
desirability to SS with high physical attractiveness $\left(F(1,141)=258.94, p<0.001\right.$, Partial $\left.\eta^{2}=0.65\right)$ and SS with high social skills $\left(F(1,141)=37.41, p<0.001\right.$, Partial $\left.\eta^{2}=0.21\right)$, in contrast to those with low physical attractiveness and low social skills, respectively (Table 2). No significant difference was observed for current or prospective social status $\left(F(1,141)=0.37, p=0.546\right.$, Partial $\left.\eta^{2}<0.01\right)$. Male participants, on the other hand, assigned greater overall desirability to SS with high physical attractiveness $(F(1,68)=75.23, p<0.001$, Partial $\left.\eta^{2}=0.53\right)$, those with high social skills $\left(F(1,68)=22.38, p<0.001\right.$, Partial $\left.\eta^{2}=0.25\right)$ and those with high social status $\left(F(1,68)=9.11, p=0.004\right.$, Partial $\left.\eta^{2}=0.12\right)$, in contrast to those with low physical attractiveness, low social skills and low social status, respectively (Table 2).

\subsection{Social Comparisons and Self-Perception}

For female participants, we observed differences in self-perception between groups exposed to SS with high physical attractiveness and groups exposed to SS with low physical attractiveness for the characteristics attractive face, attractive body and ambitious/hard working]. Significant differences were also detected between groups of female participants exposed to SS with high and low social status rankings for the characteristics attractive face and good health. For male participants, we observed a difference in self-perceived overall desirability between groups of men exposed to SS with high and those exposed to SS with low social status. No other significant differences were observed (Table 3).

In order to reveal the directions of the differences found on the self-perception we performed one sample two-tailed $t$ tests contrasting the mean difference-score between the second and the first assessments for male and female groups to the value zero (no effect). We observed that women exposed to SS with high physical attractiveness showed a decrease in their self-evaluation of ambitious/hard working characteristic $(t(80)=-2.92, p$ $=0.004, r=0.31)$ and those exposed to SS with low physical attractiveness showed an increase in their self-evaluation of the attractive face $(t(67)=2.59, p=0.012, r=0.30)$ and ambitious/hard working $(t(67)=2.06$, $p=0.044, r=0.24)$ characteristics. Women exposed to SS with low social status showed an increase in their self-evaluation of the attractive face $(t(71)=2.26, p=0.027, r=0.26)$ and good health $(t(71)=2.56, p=0.013$, $r=0.29)$ characteristics. Men exposed to SS with low social status increased their self-evaluation of overall desirability $(t(42)=2.75, p=0.009, r=0.39)$. All other means calculated were not significantly different from zero (see Table 3 for mean values).

\subsection{Social Comparisons and Mate Preferences}

Concerning short-term romantic preferences, no significant differences were observed for the characteristics evaluated by female and male participants exposed to SS with high and low physical attractiveness $(t(147)>$ -1.59, $p>0.114, r<0.13$ for female participants; $t(74)<1.19, p>0.114, r<0.14$ for male participants), social skills $(\mathrm{t}(147)<0.97, p>0.335, r<0.08$ for female participants; $t(74)>-1.46, p>0.149, r<0.17$ for male

Table 2. Participant evaluations of the overall desirability of same-gender stimulus subjects.

\begin{tabular}{|c|c|c|c|c|}
\hline & \multicolumn{2}{|c|}{ Female subjects } & \multicolumn{2}{|c|}{ Male subjects } \\
\hline & $n$ & $M(S D)$ & $n$ & $M(S D)$ \\
\hline \multicolumn{5}{|c|}{ Physical attractiveness } \\
\hline High & 81 & $58.11(17.73)$ & 38 & $54.53(18.54)$ \\
\hline Low & 68 & $21.30(12.30)$ & 38 & 22.71 (14.87) \\
\hline \multicolumn{5}{|c|}{ Social skills } \\
\hline High & 73 & $48.26(24.00)$ & 39 & $48.39(23.10)$ \\
\hline Low & 76 & $34.64(22.21)$ & 37 & 28.32 (18.42) \\
\hline \multicolumn{5}{|c|}{ Social status } \\
\hline High & 77 & $42.92(24.46)$ & 33 & $46.51(23.70)$ \\
\hline Low & 72 & 39.60 (23.58) & 43 & 32.56 (21.01) \\
\hline
\end{tabular}


Table 3. Contrasts for the difference-score for male and female participants.

\begin{tabular}{|c|c|c|c|c|c|c|c|c|}
\hline & \multicolumn{4}{|c|}{ Female subjects } & \multicolumn{4}{|c|}{ Male subjects } \\
\hline & High & Low & & & High & Low & & \\
\hline & $M(S D)$ & $M(S D)$ & $t$ & $p$ & $M(S D)$ & $M(S D)$ & $t$ & $p$ \\
\hline \multicolumn{9}{|c|}{ Physical attractiveness } \\
\hline Attractive face & $-0.20(1.22)$ & $0.37(1.17)$ & -2.87 & .005 & $-0.18(1.09)$ & $<0.01(0.99)$ & -0.77 & .442 \\
\hline Attractive body & $-0.14(1.17)$ & $0.25(1.20)$ & -1.98 & .050 & $-0.26(1.33)$ & $-0.08(1.48)$ & -0.57 & .569 \\
\hline Good health & $0.15(1.38)$ & $0.25(1.30)$ & -0.46 & .645 & $0.18(1.49)$ & $0.34(1.86)$ & -0.41 & .684 \\
\hline Good financial status & $0.31(1.18)$ & $0.34(1.10)$ & -0.16 & .875 & $0.11(1.16)$ & $0.42(1.65)$ & -0.96 & .338 \\
\hline Sociability & $0.17(1.66)$ & $-0.06(1.01)$ & 1.00 & .317 & $-0.13(0.91)$ & $0.34(1.68)$ & -1.53 & .130 \\
\hline Ambition/Hard worker & $-0.46(1.41)$ & $0.32(1.30)$ & -3.49 & .001 & $0.34(1.56)$ & $0.21(1.97)$ & 0.32 & .748 \\
\hline Intelligence & $-0.01(1.30)$ & $0.19(1.48)$ & -0.89 & .373 & $0.16(1.08)$ & $-0.03(1.44)$ & 0.63 & .530 \\
\hline Agreeableness & $-0.21(2.04)$ & $-0.13(1.64)$ & -0.25 & .801 & $-0.03(1.92)$ & $0.42(1.83)$ & -1.04 & .302 \\
\hline Sincerity & $0.28(1.55)$ & $-0.15(1.62)$ & 1.65 & .100 & $0.39(1.31)$ & $0.39(1.98)$ & 0.01 & .999 \\
\hline Overall desirability & $0.49(11.62)$ & $1.01(15.43)$ & -0.23 & .815 & 3.84 (12.31) & $0.21(17.53)$ & 1.04 & .300 \\
\hline \multicolumn{9}{|c|}{ Social skills } \\
\hline Attractive face & $0.04(1.12)$ & $0.08(1.32)$ & -0.19 & .851 & $-0.18(1.07)$ & $<0.01(1.00)$ & -0.75 & .454 \\
\hline Attractive body & $-0.03(1.15)$ & $0.11(1.24)$ & -0.68 & .500 & $-0.21(1.64)$ & $-0.14(1.11)$ & -0.22 & .829 \\
\hline Good health & $0.14(1.26)$ & $0.25(1.42)$ & -0.51 & .608 & $0.18(1.50)$ & $0.35(1.86)$ & -0.44 & .658 \\
\hline Good financial status & $0.26(1.17)$ & $0.38(1.12)$ & -0.65 & .518 & $0.15(1.77)$ & $0.38(0.95)$ & -0.68 & .497 \\
\hline Sociability & $0.05(1.49)$ & $0.08(1.32)$ & -0.10 & .917 & $0.23(1.63)$ & $-0.03(1.01)$ & 0.82 & .413 \\
\hline Ambition/Hard worker & $-0.15(1.55)$ & $-0.05(1.26)$ & -0.42 & .672 & $0.54(2.02)$ & $<0.01(1.43)$ & 1.33 & .187 \\
\hline Intelligence & $-0.08(1.43)$ & $0.24(1.33)$ & -1.41 & .160 & $0.13(1.47)$ & $<0.01(1.03)$ & 0.44 & .663 \\
\hline Agreeableness & $-0.29(1.82)$ & $-0.07(1.90)$ & -0.73 & .468 & $0.28(2.21)$ & $0.11(1.47)$ & 0.40 & .689 \\
\hline Sincerity & $0.07(1.69)$ & $0.11(1.50)$ & -0.14 & .889 & 0.59 (1.77) & $0.19(1.54)$ & 1.05 & .298 \\
\hline Overall desirability & $0.75(12.44)$ & $0.71(14.42)$ & 0.02 & .985 & $-0.21(17.54)$ & 4.38 (11.97) & -1.32 & .190 \\
\hline \multicolumn{9}{|c|}{ Current or prospective social status } \\
\hline Attractive face & $-0.17(1.26)$ & $0.31(1.15)$ & -2.40 & .018 & $-0.15(1.23)$ & $-0.05(0.87)$ & -0.44 & .664 \\
\hline Attractive body & $0.12(1.25)$ & $-0.04(1.14)$ & 0.81 & .421 & $-0.12(1.78)$ & $-0.21(1.04)$ & 0.27 & .788 \\
\hline Good health & $-0.01(1.27)$ & $0.42(1.38)$ & -1.98 & .050 & $0.30(1.74)$ & $0.23(1.65)$ & 0.18 & .857 \\
\hline Good financial status & $0.19(1.15)$ & $0.46(1.13)$ & -1.41 & .159 & $0.27(1.75)$ & $0.26(1.14)$ & 0.05 & .960 \\
\hline Sociability & $0.03(1.31)$ & $0.11(1.51)$ & -0.37 & .713 & $0.15(1.60)$ & $0.07(1.16)$ & 0.26 & .797 \\
\hline Ambition/Hard worker & $-0.19(1.37)$ & $0.00(1.45)$ & -0.84 & .401 & $-0.06(1.97)$ & $0.53(1.58)$ & -1.46 & .147 \\
\hline Intelligence & $-0.01(1.31)$ & $0.18(1.46)$ & -0.85 & .395 & $-0.18(1.53)$ & $0.26(1.00)$ & -1.50 & .137 \\
\hline Agreeableness & $-0.05(1.53)$ & $-0.31(2.16)$ & 0.83 & .407 & $0.12(1.83)$ & $0.26(1.93)$ & -0.31 & .759 \\
\hline Sincerity & $-0.03(1.44)$ & $0.21(1.74)$ & -0.90 & .372 & $0.15(1.89)$ & $0.58(1.47)$ & -1.12 & .268 \\
\hline Overall desirability & $0.35(14.75)$ & 1.14 (11.99) & -0.36 & .722 & $-2.12(17.46)$ & $5.21(12.42)$ & -2.14 & .036 \\
\hline
\end{tabular}

Note: $d f=147$ and $d f=74$ for female and male tests, respectively. The statistical differences are displayed in bold. $N=81$ for females exposed to SS with high physical attractiveness and $N=68$ for female exposed to SS with low physical attractiveness; $N=73$ for females exposed to SS with high social skills and $N=76$ for females exposed to SS with low social skills; $N=77$ for females exposed to SS with high social status and $N=72$ for females exposed to SS with low social status. $N=38$ for males exposed to SS with high physical attractiveness and $N=38$ for males exposed to SS with low physical attractiveness; $N=39$ for males exposed to SS with high social skills and $N=37$ for males exposed to SS with low social skills; $N=33$ for males exposed to SS with high social status and $N=43$ for males exposed to SS with low social status. 
participants) or social status $(t(147)>-1.87, p>0.063, r<0.15$ for female participants; $t(74)>-1.90, p>0.061$, $r<0.22$ for male participants). Considering long-term romantic preferences, female participants exposed to SS with high social skills were less demanding regarding the agreeableness of ideal romantic partners compared to female subjects exposed to SS with low social skills $(t(147)=-2.24, p=0.026, r=0.18)$. No other significant differences were observed in the characteristics evaluated for female and male participants exposed to SS with high and low physical attractiveness $(t(147)>-1.75, p>0.081, r<0.14$ for female participants; $t(74)>-1.76$, $p>0.083, r<0.20$ for male participants), social skills $(t(147)>-1.64, p>0.103, r<0.13$ for female participants; $t(74)>-1.61, p>0.112, r<0.18$ for male participants) or social status $(t(147)<1.54, p>0.127, r<0.13$ for female participants; $t(74)<1.66, p>0.101, r<0.19$ for male participants).

\section{Discussion}

In this paper we investigate the effects of intrasexual social comparisons on male and female self-perception and mate preferences. Unlike previous research, male and female participants in the current study were exposed to subject stimulus based on physical, social and status related attributes; and the contrast between pre- and post-exposure was analyzed.

The first step in this investigation was to determine how men and women imagine the opposite sex to assess the desirability of an ideal romantic partner. As predicted, female participants imagine that men value female physical attractiveness; male participants imagine that woman value male social status; and both sexes imagine that the opposite-sex values high social skills and good personality. Our results are consistent with independent observations of mate preference patterns for men and women (Buss, 1989; Buss \& Barnes, 1986; Buunk et al., 2002; Castro \& Lopes, 2011; Li, Bailey, Kenrick, \& Linsenmeier, 2002). We also observed that male participants expect women to place great value on male physical attractiveness, in fact, we observed the greatest effect in physical attractiveness contrasts for both sexes. Although, in accordance with the literature on mate preference, men are not expected to consider physical attractiveness to play an important role in female evaluation of male desirability and this result may be due to the sample used in this study, which were university undergraduates in their early 20s with similar family backgrounds and mostly financially dependent on their parents. We suggest that physical attractiveness becomes more relevant in the mating marketplace when the individuals involved share similar social and financial conditions. Moreover, female preference for physically attractive partners increases when they are seeking short-term relationships (for demographically similar individuals, see Castro \& Lopes, 2011), the most common kind of relationship among college students (Lambert, Kahn, \& Apple, 2003; Owen, Fincham, \& Moore, 2011; Owen, Rhoades, Stanley, \& Fincham, 2010).

Exposure to same-gender stimuli subjects with high and low physical attractiveness indeed affected the self-perception of female participants: those exposed to less attractive women described their own faces as being more attractive. It has been suggested that female physical attractiveness is related to reproductive health (Weeden \& Sabini, 2005) and previously described as an important attribute in opposite-sex evaluation. An interesting finding in the current study, was that exposure to rivals with different physical attributes not only affected the participants' assessment of physical characteristics, it also affected their assessment of status characteristics. One explanation for this observation is that attractive people usually have greater benefits in the labor market (Hamermesh \& Biddle, 1994; Hosoda, Stone-Romero, \& Coats, 2003) and are perceived as being more sociable, intelligent, socially skilled and dominant (Feingold, 1992) and, that perhaps female participants are aware of this. Alternatively, although it was not measured in this study, exposure to high and low attractive women may have affected female self-esteem and thus, motivation; while exposure to attractive women only seems to have a negative effect on female self-esteem (Wilcox \& Laird, 2000). Male participants were not affected by the physical attractiveness of stimuli subjects. Although they recognize that physical characteristics are important to the females present in their marketplace, male mate value is not strongly related to physical attractiveness. This result is not consistent with other studies that observed changes in male self-evaluations after exposure to physically attractive men (Blond, 2008; Wade \& McCrea, 1999). However, in this study, participants were not asked to explicitly compare themselves to any male profiles, nor were they exposed to muscular men.

As expected, male participants changed their self-perception after being exposed to men with different levels of social status. This difference was observed among those exposed to men of low social status, who showed an increase in their own sense of overall desirability following exposure. Male social status and access to resources is a well described female preference and, as previously shown, male participants are aware of it. However, no 
changes were observed in male participants exposed to men of high social status. We suggest that a decrease in self-assessments after exposure to high-status subject stimuli was not observed here because the sample was composed of young males just starting college (that have not faced labor market yet). From the perspective of this position, these male subjects can aspire to becoming just as successful as the profiles they been shown in the future. Additional studies may help to explain this issue by using different sample compositions or stimulus subjects that are closer to the academic environment of a sample of undergraduate students.

An unexpected result was observed for also observed for the female participants. After being exposed to low-status women, they increased their self-perceived health and facial attractiveness. One explanation for this finding is that, from the point of view of these female participants, low-status in women may be positively related to low physical attractiveness and poor health, so the contrast with these subject stimuli had the effect of increasing the self-evaluations of these same characteristics by participants. This result can be interpreted as evidence that perceptions of mate value are based on a joint assessment of different attributes (Castro \& Lopes, 2011; Fisher et al., 2008).

Our prediction that participants exposed to same-gender stimuli subjects with high and low social skills would show a change in their self-perception was not confirmed by this study. This result was not expected because characteristics related to a desirable personality and good social skills are known to be the most valued attributes in romantic partners (Buss, 1985). However, the lack of sensitivity to these characteristics observed here may be due to the fact that the evaluation of such attributes is affected by subjective judgments, which have to be measured relative to another person and in a specific context, which was not a part of this study. In contrast to physical attributes and status signals, behavioral characteristics are not easily assessed and may be subject to falsification. We believe that a proper evaluation of these attributes takes time and is associated with experience. Thus, information about the behavior of other people can help guide one's own behavior toward that person, but may be not enough to have a measurable effect on self-perception.

Predictions regarding the effect of same-gender social comparisons on mate preferences were also not confirmed by this study. We only observed that female participants were less demanding in their perceptions of desirability for ideal long-term romantic partners after being exposed to stimuli subjects with high social skills. One possible explanation for the absence of observable effects under this scenario is that mate preferences may not be so sensitive to current social comparisons because they have been previously selected for adaptive advantages that facilitated successful reproduction among our ancestors. Once the value of reproductively relevant characteristics do not change as a function of other people's characteristics, changes based on social contrast would not be adaptive and, therefore, would not be expected to occur. Moreover, social mechanisms, such as social norms, beliefs or cultural values, would become more important in determining mate preferences. Alternatively, the sample size was probably not large enough to aggregate the statistical power necessary to reveal genuine effects.

It is important to highlight that, to the best of our knowledge, this is the first study of its kind to address social contrasts by using specifically designed profiles based on a diverse set of attributes. In order to keep the contrasts closer to what is expected in real life events, we did not explicitly ask the participants to contrast themselves with the subject stimuli. For that reason, we believe that the effect of social comparison observed in this study may be underestimated. Explicit comparisons may make people more aware of their own attributes and increase the contrast effect; however there is no reason to expect this sort of comparison to be a predominant occurrence in real life scenarios. In addition, we were looking for general effects, so maybe the response to social comparison in this context is related to individual differences (condition dependent responses). The available literature on this subject indicates that there are groups of people who show higher sensibility to the contrast effect (Harrison et al., 2006; Mills, Polivy, Herman, \& Tiggemann, 2002; Wilcox \& Laird, 2000).

The present study is also based on a sample from a country (Brazil) with one of the most ethnically diverse populations in the world. However, this diversity is not equally distributed throughout the country. Hence, we expect this study to provide cues (directions) about the effect of social comparison on mate value and mate preferences, and not a definitive picture of the effects of social comparisons in the whole Brazilian mating market. Samples from different regions and/or with different socio-demographic characteristics might show different responses. Moreover, Brazil is different from the USA, where most surveys of this kind have been carried out so far. This situation provides us with an opportunity to study the effects of social comparisons on self-evaluations and mate preferences across various cultures.

There are several notable limitations to the current study. One is that a larger and more uniform sample for 
each gender group could reveal a clearer contrast between gender responses and improve the overall statistical power. Sampling a cross section of the community to include people with different financial/educational backgrounds and testing the effect among different age groups would certainly improve the generalization of results, compared to sampling a single cohort of university undergraduates The experiment could also be expanded by incorporating different stimuli, including other specific personality/physical characteristics and by contrasting different groups of participants to reveal important information about individual sensibility and the effect of social contrast on short- or long-term mating tactics. Incorporating more complete assessments of self-esteem might also reveal more detailed effects and help to understand the observed changes.

\section{Conclusion}

In conclusion, the findings presented here do serve to advance our overall understanding of the mate selection process by demonstrating the direct effect of same-gender social comparisons on self-perception. Sensibility to reproductively relevant attributes can help individuals optimize their investment of energy in the mating marketplace and help them choose the mating tactic that is most consistent with their own social environment. The mate selection process seems to be similar to a biological market in which ones mate value seems to be affected by the perceived value of other individuals in the population.

\section{References}

Bardel, M., Fontayne, P., Colombel, F., \& Schiphof, L. (2010). Effects of Match Result and Social Comparison on Sport State Self-Esteem Fluctuations. Psychology of Sport and Exercise, 11, 171-176. http://dx.doi.org/10.1016/j.psychsport.2010.01.005

Bereczkei, T., Voros, S., Gal, A., \& Bernath, L. (1997). Resources, Attractiveness, Family Commitment; Reproductive Decisions in Human Mate Choice. Ethology, 103, 681-699. http://dx.doi.org/10.1111/j.1439-0310.1997.tb00178.x

Blond, A. (2008). Impacts of Exposure to Images of Ideal Bodies on Male Body Dissatisfaction: A Review. Body Image, 5, 244-250. http://dx.doi.org/10.1016/j.bodyim.2008.02.003

Brase, G. L., \& Guy, E. C. (2004). The Demographics of Mate Value and Self-Esteem. Personality and Individual Differences, 36, 471-484. http://dx.doi.org/10.1016/S0191-8869(03)00117-X

Bredow, C. A., Huston, T. L., \& Glenn, N. D. (2011). Market Value, Quality of the Pool of Potential Mates, and Singles' Confidence about Marrying. Personal Relationships, 18, 39-57. http://dx.doi.org/10.1111/j.1475-6811.2010.01302.x

Brown, S. L. (2000). Union Transitions among Cohabitors: The Significance of Relationship Assessments and Expectations. Journal of Marriage and Family, 62, 833-846. http://dx.doi.org/10.1111/j.1741-3737.2000.00833.x

Buss, D. M. (1985). Human Mate Selection: Opposites Are Sometimes Said to Attract, But in Fact We Are Likely to Marry Someone Who Is Similar to Us in Almost Every Variable. American Scientist, 73, 47-51.

Buss, D. M. (1989). Sex Differences in Human Mate Preferences: Evolutionary Hypotheses Tested in 37 Cultures. Behavioral and Brain Sciences, 12, 1-49. http://dx.doi.org/10.1017/S0140525X00023992

Buss, D. M., \& Barnes, M. (1986). Preferences in Human Mate Selection. Journal of Personality and Social Psychology, 50, 559-570. http://dx.doi.org/10.1037/0022-3514.50.3.559

Buss, D. M., \& Schmitt, D. P. (1993). Sexual Strategies Theory: An Evolutionary Perspective on Human Mating. Psychological Review, 100, 204-232. http://dx.doi.org/10.1037/0033-295X.100.2.204

Buss, D. M., Shackelford, T. K., Kirkpatrick, L. A., \& Larsen, R. J. (2001). A Half Century of Mate Preferences: The Cultural Evolution of Values. Journal of Marriage and Family, 63, 491-503. http://dx.doi.org/10.1111/j.1741-3737.2001.00491.x

Buston, P. M., \& Emlen, S. T. (2003). Cognitive Processes Underlying Human Mate Choice: The Relationship between Self-Perception and Mate Preference in Western Society. Proceedings of the National Academy of Sciences of the United States of America, 100, 8805-8810. http://dx.doi.org/10.1073/pnas.1533220100

Buunk, B. P., Dijkstra, P., Fetchenhauer, D., \& Kenrick, D. T. (2002). Age and Gender Differences in Mate Selection Criteria for Various Involvement Levels. Personal Relationship, 9, 271-278. http://dx.doi.org/10.1111/1475-6811.00018

Castro, F. N., \& Lopes. F. A. (2011). Romantic Preferences in Brazilian Undergraduate Students: From the Short Term to the Long Term. Journal of Sex Research, 48, 479-485. http://dx.doi.org/10.1080/00224499.2010.506680

Castro, F. N., Hattori, W. T., \& Lopes. F. A. (2012). Relationship Maintenance or Preference Satisfaction? Male and Female Strategies in Romantic Partner Choice. Journal of Social, Evolutionary \& Cultural Psychology, 6, 217-226.

http://dx.doi.org/10.1037/h0099213 
Feingold, A. (1992). Good-Looking People Are Not What We Think. Psychological Bulletin, 111, 304-341. http://dx.doi.org/10.1037/0033-2909.111.2.304

Festinger, L. (1954). A Theory of Social Comparison Processes. Human Relations, 7, 117-140. http://dx.doi.org/10.1177/001872675400700202

Fisher, M., Cox, A., Bennett, S., \& Gavric, D. (2008). Components of Self-Perceived Mate Value. Journal of Social, Evolutionary, and Cultural Psychology, 2, 156-168. http://dx.doi.org/10.1037/h0099347

Gallant, S., Williams, L., Fisher, M., \& Cox, A. (2011). Mating Strategies and Self-Presentation in Online Personal Advertisement Photographs. Journal of Social, Evolutionary, and Cultural Psychology, 5, 106-121. http://dx.doi.org/10.1037/h0099272

Gilbert, P., Price, J., \& Allan, S. (1995). Social Comparison, Social Attractiveness and Evolution: How Might They Be Related? New Ideas in Psychology, 13, 149-165. http://dx.doi.org/10.1016/0732-118X(95)00002-X

Groesz, L. M., Levine, M. P., \& Murnen, S. K. (2002). The Effect of Experimental Presentation of Thin Media Images on Body Satisfaction: A Meta-Analytic Review. International Journal of Eating Disorders, 31, 1-16. http://dx.doi.org/10.1002/eat.10005

Grogan, S., Williams, Z., \& Conner, M. (1996). The Effects of Viewing Same-Gender Photographic Models on Body-Esteem. Psychology of Women Quarterly, 20, 569-575. http://dx.doi.org/10.1111/j.1471-6402.1996.tb00322.x

Gutierres, S. E., Kenrick, D. T., \& Partch, J. J. (1999). Beauty, Dominance, and the Mating Game: Contrast Effects in Self-Assessment Reflect Gender Differences in Mate Selection. Personality and Social Psychology Bulletin, 25, 1126-1134. http://dx.doi.org/10.1177/01461672992512006

Hamermesh, D. S., \& Biddle, J. E. (1994). Beauty and the Labor Market. American Economic Association, 84, $1174-1194$.

Harrison, K., Taylor, L. D., \& Marske, A. L. (2006). Women’s and Men’s Eating Behavior Following Exposure to Ideal-Body Images and Text. Communication Research, 33, 507-529. http://dx.doi.org/10.1177/0093650206293247

Hill, R. (1945). Campus Values in Mate Selection. Journal of Home Economics, 37, 554-558.

Hosoda, M., Stone-Romero, E. F., \& Coats, G. (2003). The Effects of Physical Attractiveness on Jog-Related Outcomes: A Meta-Analysis of Experimental Studies. Personnel Psychology, 56, 431-462. http://dx.doi.org/10.1111/j.1744-6570.2003.tb00157.x

Instituto Brasileiro de Geografia e Estatística (IBGE) (2010a). Censo demográfico 2010: Resultados do universo—características da população e dos domicílios (Tabela 3175). http://www.sidra.ibge.gov.br/cd/cd2010universo.asp?o=7\&i=P

Instituto Brasileiro de Geografia e Estatística (IBGE) (2010b). Síntese de indicadores sociais: Uma análise das condições de vida da população brasileira, estudos \& pesquisas: Informação demográfica e socioeconômica [Synthesis of Social Indicators: An Analysis of the Living Conditions of the Brazilian Population, Studies \& Surveys: Demographic and Socioeconomic Information] (número 27). Rio de Janeiro: Author.

Kemmelmeier, M., \& Oyserman, D. (2001). The Ups and Downs of Thinking about a Successful Other: Self-Construals and the Consequences of Social Comparisons. European Journal of Social Psychology, 31, 311-320. http://dx.doi.org/10.1002/ejsp.47

Kenrick, D. T., Sadalla, E. K., Groth, G., \& Trost, M. R. (1990). Evolution, Traits, and the Stages of Human Courtship: Qualifying the Parental Investment Model. Journal of Personality, 58, 97-116. http://dx.doi.org/10.1111/j.1467-6494.1990.tb00909.x

Lambert, T. A., Kahn, A. S., \& Apple, K. J. (2003). Pluralistic Ignorance and Hooking Up. The Journal of Sex Research, 40, 129-133. http://dx.doi.org/10.1080/00224490309552174

Li, N. P., Bailey, J. M., Kenrick, D. T., \& Linsenmeier, J. A. (2002). The Necessities and Luxuries of Mate Preferences: Testing the Tradeoffs. Journal of Personality and Social Psychology, 82, 947-955. http://dx.doi.org/10.1037/0022-3514.82.6.947

Lippa, R. A. (2007). The Preferred Traits of Mates in a Cross-National Study of Heterosexual and Homosexual Men and Women: An Examination of Biological and Cultural Influences. Archives of Sexual Behavior, 36, 193-208. http://dx.doi.org/10.1007/s10508-006-9151-2

Little, A. C., \& Mannion, H. (2006). Viewing Attractive or Unattractive Same-Sex Individuals Changes Self-Rated Attractiveness and Face Preferences in Women. Animal Behaviour, 72, 981-987. http://dx.doi.org/10.1016/j.anbehav.2006.01.026

Little, A. C., Burt, D. M., Penton-Voak, I. S., \& Perrett, D. I. (2001). Self-Perceived Attractiveness Influences Human Female Preferences for Sexual Dimorphism and Symmetry in Male Faces. Proceedings of the Royal Society of London B, 268, 39-44. http://dx.doi.org/10.1098/rspb.2000.1327

McGinnis, R. (1958). Campus Values in Mate Selection: A Repeat Study. Social Forces, 36, 368-373. 
http://dx.doi.org/10.2307/2573978

Mills, J. S., Polivy, J., Herman, C. P., \& Tiggemann, M. (2002). Effects of Exposure to Thin Media Images: Evidence of Self-Enhancement among Restrained Eaters. Personality and Social Psychology Bulletin, 28, 1687-1699. http://dx.doi.org/10.1177/014616702237650

Mulford, M., Orbell, J., Shatto, C., \& Stockard, J. (1998). Physical Attractiveness, Opportunity, and Success in Everyday Exchange. American Journal of Sociology, 103, 1565-1592. http://dx.doi.org/10.1086/231401

Owen, J. J., Rhoades, G. K., Stanley, S. M., \& Fincham, F. (2010). “Hooking Up” among College Students: Demographic and Psychosocial Correlates. Archives of Sexual Behavior, 39, 653-663. http://dx.doi.org/10.1007/s10508-008-9414-1

Owen, J., Fincham, F. D., \& Moore, J. (2011). Short-Term Prospective Study of Hooking Up among College Students. Archives of Sexual Behavior, 40, 331-341. http://dx.doi.org/10.1007/s10508-010-9697-x

Sprecher, S., Sullivan, Q., \& Hatfield, E. (1994). Mate Selection Preferences: Gender Differences Examined in a National Sample. Journal of Personality and Social Psychology, 66, 1074-1080. http://dx.doi.org/10.1037/0022-3514.66.6.1074

Stapel, D. A., \& Blanton, H. (2004). From Seeing to Being: Subliminal Social Comparison Affect Implicit and Explicit SelfEvaluations. Journal of Personality and Social Psychology, 87, 468-481. http://dx.doi.org/10.1037/0022-3514.87.4.468

Suls, J., Martin, R., \& Wheeler, L. (2002). Social Comparison: Why, with Whom and with What Effect? Current Directions in Psychological Science, 11, 159-163. http://dx.doi.org/10.1111/1467-8721.00191

Taylor, S. E., \& Lobel, M. (1989). Social Comparison Activity under Threat: Downward Evaluation and Upward Contacts. Psychological Review, 96, 569-575. http://dx.doi.org/10.1037/0033-295X.96.4.569

Trivers, R. L. (1972). Parental Investment and Sexual Selection. In B. Campbell (Ed.), Sexual Selection and the Descent of Man, 1871-1971 (pp. 136-179). Chicago, IL: Aldine.

Vukovic, J., Feinberg, D. R., Jones, B. C., DeBruine, L. M., Welling, L. L. M., Little, A. C., \& Smith, F. G. (2008). Self-Rated Attractiveness Predicts Individual Differences in Women's Preferences for Masculine Men’s Voices. Personality and Individual Differences, 45, 451-456. http://dx.doi.org/10.1016/j.paid.2008.05.013

Wade, T. J. (2000). Evolutionary Theory and Self-Perception: Sex Differences in Body Esteem Predictors of Self-Perceived Physical and Sexual Attractiveness and Self-Esteem. International Journal of Psychology, 35, 36-45. http://dx.doi.org/10.1080/002075900399501

Wade, T. J. (2003). Evolutionary Theory and African American Self-Perception: Sex Differences in Body-Esteem Predictors of Self-Perceived Physical and Sexual Attractiveness, and Self-Esteem. Journal of Black Psychology, 29, 123-141. http://dx.doi.org/10.1177/0095798403029002001

Wade, T. J., \& McCrea, S. (1999). Intrasexual Competition and Contrast Effects on Men’s Self-Ratings of Attractiveness and Social Ascendancy. Psychology, Evolution \& Gender, 1, 229-243.

Waller, M. R., \& McLanahan, S. S. (2005). “His” and “Her” Marriage Expectations: Determinants and Consequences. Journal of Marriage and Family, 67, 53-67. http://dx.doi.org/10.1111/j.0022-2445.2005.00005.X

Weeden, J., \& Sabini, J. (2005). Physical Attractiveness and Health in Western Societies: A Review. Psychological Bulletin, 131, 635-653. http://dx.doi.org/10.1037/0033-2909.131.5.635

Weeden, J., \& Sabini, J. (2007). Subjective and Objective Measures of Attractiveness and Their Relation to Sexual Behavior and Sexual Attitudes in University Students. Archives of Sexual Behavior, 36, 79-88. http://dx.doi.org/10.1007/s10508-006-9075-x

Wilcox, K., \& Laird, J. D. (2000). The Impact of Media Images of Super-Slender Women on Women’s Self-Esteem: Identification, Social Comparison, and Self-Perception. Journal of Research in Personality, 34, 278-286. http://dx.doi.org/10.1006/jrpe.1999.2281

Woodward, K., \& Richards, M. H. (2005). The Parental Investment Model and Minimum Mate Choice Criteria in Humans. Behavioral Ecology, 16, 57-61. http://dx.doi.org/10.1093/beheco/arh121 